\title{
Special Issue: The Economics of Inequality
}

\author{
Wilfried Altzinger ${ }^{1} \cdot$ Giacomo $^{\text {Corneo }^{2}}$. \\ Agnes Kügler ${ }^{3}$
}

In summer 2013 the Austrian Economic Association decided to organize its 2014 annual conference on the topic of "Economics of Inequality". At that time both the OECD and the IMF had already published numerous research papers on the issue of economic inequality. However, Thomas Piketty's bestseller "Capital in the 21st Century" had only been published in French. In March 2014, when the English version of Piketty's book was published, the deadline for submissions to the conference was already over. Still, the organizers received more submissions to the conference than ever before. What is the reason for the enormous interest in inequality?

In one of his most influential papers on inequality, Sir Anthony B. Atkinson (1997) called for "Bringing income distribution in from the cold". Since the beginning of the new century, this "call" has been rather successful. In particular, a group of economists around A. Atkinson, T. Piketty, E. Saez and F. Alvaredo has published numerous new papers and books on this issue. Atkinson and Bourguignon (2015) have just recently published a nearly all-encompassing 2,250 page-long 2nd volume of the handbook on income distribution.

Wilfried Altzinger

altzing@wu.ac.at

Giacomo Corneo

giacomo.corneo@fu-berlin.de

Agnes Kügler

Agnes.Kuegler@wifo.ac.at

1 Vienna University of Economics and Business, Wien, Austria

2 Free University of Berlin, Berlin, Germany

3 Austrian Institute of Economic Research, Wien, Austria 
Growing income and wealth inequality has started to loom large in public debates and policy discussions. Indeed, in most OECD countries and many emerging economies, the gap between the rich and the poor has widened over the past decades. The rise of this 'great divide' coincided with a period of sustained economic growth prior to the Great Recession. Since 2008 the economic crisis has put additional pressure on the issue of the distribution of income and wealth, raising several economic, political, and ethical challenges.

The conference took place in the Department of Economics at the Vienna University of Economics and Business on 30-31 May 2014. The organizers were rightly proud to show their brand-new campus, which was a great appeal to all participants. Overall the conference comprised 27 sessions with a total of 99 papers. Exactly 60 of these papers dealt with the main topic of the conference, the 'Economics of Inequality.' From those papers, a selection was submitted to the special issue of Empirica, among which a final set of nine papers was accepted for publication. In addition, both keynote lectures by Giacomo Corneo and Sir Antony B. Atkinson are included in this special issue. All of these papers contain new empirical research.

Sir Anthony B. Atkinson, whom Robert Solow (2014) recently called the "pioneer and gray eminence of modern inequality studies", starts his keynote on "Can we reduce income inequality in OECD countries?" with a rather interesting but frequently neglected reflection about the economic and political discussion on inequality by quoting the English Proverb "Fine words butter no parsnips"nothing is achieved by empty words. Atkinson refutes the nihilistic views that 'nothing can be done to stop increasing inequalities', in three sub-sections. First he discusses the experience of the post-war decades in Europe where inequalities were decisively reduced by a decline in the share of capital income and in the concentration of wealth, as well as by equalizing labour market policy, and intensified redistribution via the welfare state and progressive taxes. Further, he investigates the reasons for the reversal for these policies since the early 1980s. Atkinson focuses on the issues of globalization and technological change, which are examined via a standard but dynamically extended textbook story. He concludes that policies which try to reduce the extent of inequalities have to be concerned not only about human capital formation but also about the techniques of production. Finally, new developments of the standard production function with an elasticity of substitution greater than one are discussed. This implies that the increase of the capital/labour-ratio is stronger than the corresponding decline of the profit/wageratio, resulting in a rising profit share. Atkinson concludes that if a kind of 'robotisation' starts to replace labour without any appropriate adjustment of the profit/wage-ratio, one "may need to look at a situation where the state acquires beneficial ownership (not control) of productive capital and uses the profits to share the benefits among all citizens". Interestingly, a similar approach (originally developed by James Meade in 1964) is also discussed at great length in the new book by Giacomo Corneo (2014). To conclude, it is encouraging how many ways forward might be possible if one is seriously inclined to decrease income and wealth inequalities. 
However, Giacomo Corneo does not focus his keynote on the aforementioned issues. Instead, he presents results of the distribution of lifetime and annual earnings for cohorts born between 1935 and 1972 for Germany using data from the German social security system-the first time this has been done. Since individuals nearly always have rather different incomes at various stages of their lifecycle and working career, economists are always much more interested in inequalities over the lifecycle instead of in any given year. The results of his paper show two interesting features. First, as expected by theory, inequalities of annual earnings are much larger than inequalities of lifetime earnings. However, much more importantly and entirely new to the literature, is the fact that lifetime inequality has strongly increased for the younger cohorts over time. For West German men born in 1972, lifetime earnings inequality is predicted to be the double of what it is for those born in 1935. This strong increase of inequality is due to both longer unemployment spells for the low-skilled and to larger pay uncertainties over the lifecycle of the younger cohorts. As stressed by the author, such intergenerational effects may deeply affect our societies but remain unnoticed by focusing on annual earnings disparities only.

Partly due to new theoretical approaches but mainly as a result of newly available data, the research focus on economic inequalities has shifted into new directions during the last decade. First, it has become common sense that it is at least as important to focus on the distribution of wealth as on the distribution of income. Second, and related to the first point, research concentrating on the distribution of capital income has intensified (see in particular the contribution by Anthony B. Atkinson). For years it has been claimed that wealth is much more unequally distributed than income (see Atkinson 1972) and we now have better data than ever before to test this hypothesis empirically. Since all papers of this special issue are empirical studies, a lot of new insights on the relationship and interconnectedness of income and wealth are presented.

Using EU-SILC data for 16 EU countries, Eva Schlenker and Kai D. Schmid show for the period 2005-2011 that capital income shares are positively related with the concentration of gross household incomes. A one percentage point increase in the capital income share is associated with a 0.8 percentage point increase in the Gini coefficient of gross household income. The results of this paper reiterate the importance of focusing in particular on capital incomes when analyzing overall income inequality.

In 2013 the European Central Bank (ECB) published a brand-new data collection from the "Household Finance and Consumption Survey" (HFCS), which is publicly available. At the conference, more than ten of the presented papers were based on these data. ${ }^{1}$ Three of them are included in this Special Issue. Peter Lindner provides in his paper "Factor Decomposition of the Wealth Distribution in the Euro Area" a descriptive overview of the distribution of wealth in the euro area as a whole as well as for 15 euro area countries. In addition, he measures the contributions of the different sub-categories of wealth to the overall distribution. Although the results

\footnotetext{
${ }^{1}$ All papers of the conference as well as streams from the keynote lectures and the plenary session can be looked at: http://www2.wu.ac.at/noeg2014/.
} 
differ to some extent by the method used, he shows that a households' main residence is the highest contributor to overall wealth inequality. The paper on "Socioeconomic structures of the Austrian wealth distribution" by Stefan Humer, Mathias Moser, and Matthias Schnetzer provides detailed findings on the socioeconomic components of wealth across different quantiles of the wealth distribution. Not surprisingly, but interestingly, the lower and the upper quantiles present a completely different structure by wealth components. Looking at the top, the results indicate the importance of being self-employed and having received inheritances for wealth accumulation. Finally, the paper on "Who Holds Risky Assets and How Much?" by Jun Chao Zhan focuses on the different structure between risky and non-risky asset holders, mainly in seven euro area countries. The results suggest that riskiness differs very much by net wealth levels. Risky asset holders are considerably wealthier, more likely to be male, married, full/part owners of their main residence, better educated, and self-employed.

The paper by Markus Grabka on "Income and wealth inequality after the financial crisis - the case of Germany" is based on data from the German Socio Economic Panel (SOEP). Potential effects of the financial crisis on income can be calculated on an annual basis whilst its impacts on wealth components are available only for the years 2002, 2007 and 2012. Surprisingly, the results of this study indicate a lack of any significant distributional changes between 2007 and 2012. Grabka discusses his findings in detail and provides some evidence that the ups and downs within the 6-year period might have cancelled out each other. Finally, the author mentions the main weakness of this data set, namely the underrepresentation of top-income and top-wealth individuals and households. This data issue may, at least to some extent, explain these controversial results.

In the paper on "Inequality and household debt" by Mathias Klein, the link between income inequality and household debt is scrutinized for nine industrialized countries for the period 1953-2008. Data are used from many different sources (WTID, OECD, BIS, among others). The author concludes that in the long-run, the effect of a one-percentage point increase in inequality is associated with an increase in household credit between 2 and $6 \%$, depending on the inequality measure used.

The paper by Alyssa Schneebaum, Bernhard Rumplmaier and Wilfried Altzinger addresses yet another element of economic inequality. The authors discuss the issue of intergenerational educational mobility with a particular focus on gender, using data from the 2010 European Social Survey for 20 European countries. Since the age of the respondents of that survey ranges from 25 to 90 years, they can detect changes in intergenerational persistence over time. The results of their study are threefold. First, they confirm the hypothesis that the Nordic countries are the most mobile ones. Additionally, they find two new results. First, they observe increasing intergenerational mobility over time only for the Nordic and the Southern European countries but not for Continental Europe and the Anglo-Saxon countries. Finally, they provide evidence that this change in mobility is due mainly to an increase of female mobility.

The final paper in this special issue is a contribution by Lorenzo Cicatiello, Giuseppe Gaeta and Salvatore Ercolano on "Income Distribution and Political Participation." The authors use individual data from the European Values Study, 
which includes observations collected between 2008 and 2010. The purpose of the paper is to analyze the different interactions between individuals' income position and their involvement in political activities. The authors distinguish between 'conventional' and 'unconventional' forms of political participation. While the first category includes activities that are structurally embedded in the political system (i.e. voting, party membership, etc.), the latter consists of actions that are considered non-institutionalized (i.e. boycotting, petitioning, etc.). First, they confirm that individual incomes have a positive and significant effect on both conventional and unconventional forms of political participation. Additionally, they conclude that overall inequality is negatively related to income in explaining unconventional political participation, whilst this is not the case for conventional political participation.

Nearly all papers in this issue provide a discussion of the economic, social, and policy implications of their empirical results. With this special issue, the organizing committee of the conference has sought to bring the results of the conference to a broader public audience. Hence we are especially grateful to the Ministry of Social Affairs, the Chamber of Labour, the government of the City of Vienna, the Austrian Central Bank, and several other funding institutions not only for their financial support but more so for their lively participation to the conference. In addition, we also appreciate the broad media coverage of the conference, which was due in part to the broad public announcement of the conference, the free access to the plenary sessions for an interested audience, and finally to the free access for students. In particular, these features should be maintained for all upcoming conferences of the Austrian Economic Association. Let's hope that this conference has at least achieved something more than "Fine words butter no parsnips".

\section{References}

Atkinson AB (1972) Unequal shares: wealth in Britain. The Penguin Press, Allen Lane, London Atkinson AB (1997) Bringing income distribution in from the cold. Econ J 107:297-321

Atkinson AB, Bourguignon F (2015) Handbook of income distribution, vol 2. North-Holland, Elsevier, pp $1-2251$

Corneo G (2014) Bessere Welt-Hat der Kapitalismus ausgedient?Eine Reise durch alternative Wirtschaftssysteme. Goldegg Verlag, Wien

Meade JE (1964) Efficiency, equality and the ownership of property. Allen and Unwin, London Piketty T (2014) Capital in the twenty-first century. Harvard University Press, Cambridge

Solow RM (2014) Capital in the twenty-first century (trans: Thomas Piketty, Arthur Goldhammer). Belknap Press http://www.newrepublic.com/article/117429/capital-twenty-first-century-thomaspiketty-reviewed 